Abstracta Iranica Abstracta Iranica

Revue bibliographique pour le domaine irano-aryen

Volume 22 | 2001

Comptes rendus des publications de 1999

Essays on Islamic Piety and Mysticism. Translated by John O'Kane with editorial assistance of Bernd Radtke, Leiden, Brill, 1999, 750 p.

Pierre Lory

(2) OpenEdition

Journals

Édition électronique

URL : http://journals.openedition.org/abstractairanica/36845

DOI : 10.4000/abstractairanica.36845

ISSN : 1961-960X

Éditeur :

CNRS (UMR 7528 Mondes iraniens et indiens), Éditions de l'IFRI

Édition imprimée

Date de publication : 15 mai 2001

ISSN : 0240-8910

Référence électronique

Pierre Lory, «Essays on Islamic Piety and Mysticism. Translated by John O'Kane with editorial assistance of Bernd Radtke, Leiden, Brill, 1999, 750 p. », Abstracta Iranica [En ligne], Volume 22 | 2001 document 380, mis en ligne le 17 février 2010, consulté le 10 octobre 2020. URL : http://

journals.openedition.org/abstractairanica/36845; DOI : https://doi.org/10.4000/abstractairanica 36845

Ce document a été généré automatiquement le 10 octobre 2020

Tous droits réservés 


\title{
Essays on Islamic Piety and Mysticism. Translated by John O'Kane with editorial assistance of Bernd Radtke, Leiden, Brill, 1999, 750 p.
}

\author{
Pierre Lory
}

L'œuvre scientifique de F. Meier (1912-1998) répartie dans ses nombreux articles avait été regroupée dans les trois volumes de Bausteine. Ausgewählte Aufsätze zum Islamwissenschaft en 1992. Cependant, comme le font remarquer B. Radtke et J. O'Kane dans leur préface, la recherche en langue allemande reste fort mal connue dans le monde. La prédominance de la langue anglaise est devenue telle qu'on ne peut pas s'attendre à ce que des textes scientifiques soient connus même des spécialistes du domaine. D'où l'initiative de susciter la présente traduction, effectuée par J. O'Kane avec beaucoup de compétence et de précision. Les éditeurs ont retenu 15 articles pour le présent volume, relevant de la mystique, mais aussi de l'islamologie plus généralement. Mentionnons ceux qui concernent plus précisément le monde iranien, comme son article pionnier sur les modalités diverses et les articulations du sama $\bar{a}^{\star}$ et le $\underline{\text { dikr }}$ («The Dervish Dance ») qui reste toujours riche et utile, même s'il s'est trouvé complété ultérieurement par d'autres travaux comme ceux de M. Molé ou J. During. Ses analyses de textes restent toujours des références, comme celle du Adab al-murìdin de Najm al-dīn Kubrā ( of Etiquette for Sufis ») du Tartīb al-sulūk de Qušayrī, de l'échange épistolaire entre Šaraf al-dīn Balîī et Majd al-dīn Bağdādī, ou de l'article « An important manuscript find for Sufism » qui avait ajouté un matériel nouveau important sur al-Ḥallāj et sur le Adab al-mulūk (édité depuis par B. Radtke) notamment. L'histoire du soufisme est elle aussi représentée, notamment par le décisif «Khurasan and the End of Classical Sufism». Reprenant un thème abordé précédemment, F. Meier y recherche les étapes du passage de l'ancienne forme d'enseignement mystique par enseignement public du šayH alta'līm, à celle du šayH al-tarbiya qui s'y substitua vers les $10^{\mathrm{e}}-11^{\mathrm{e}} \mathrm{s}$., se généralisant dans le cadre du soufisme confrérique. La démonstration est menée notamment avec l'examen des successions de maîtres dans la ville de Nayšāpūr du $9^{\mathrm{e}}$ au $11^{\mathrm{e}} \mathrm{s}$. Il est sûr 
que l'œuvre de Meier va se trouver plus accessible au public international ; mais cette acceptation $\mathrm{du}$ « tout anglais » donne aussi à réfléchir.

INDEX

Thèmes : 8 . Soufisme

AUTEURS

PIERRE LORY

EPHE - Paris 